\title{
Clinical significance of metabotropic glutamate receptor 5 expression in oral squamous cell carcinoma
}

\author{
SO-YEON PARK ${ }^{2 *}$, SEOUNG-AE LEE ${ }^{*}$, IN-HEE HAN ${ }^{1}$, BYONG-CHUL YOO $^{1}$, \\ SEUNG-HOON LEE ${ }^{1}$, JO-YONG PARK ${ }^{1}$, IN-HO CHA ${ }^{3}$, JIN KIM $^{4}$ and SUNG-WEON CHOI ${ }^{1}$ \\ ${ }^{1}$ Research Institute and Hospital, National Cancer Center, Goyang, Gyeonggi; ${ }^{2}$ Department of Pathology, \\ College of Medicine, Seoul National University; Departments of ${ }^{3}$ Oral and Maxillofacial Surgery, \\ ${ }^{4}$ Oral Pathology, College of Dentistry, Yonsei University, Seoul, Korea
}

Received August 16, 2006; Accepted September 25, 2006

\begin{abstract}
The multifunctional G-protein-coupled metabotropic glutamate receptor (mGluR) family comprises eight subtypes, some of which participate in tumorigenesis. The purpose of this study was to evaluate mGluR5 expression in oral squamous cell carcinoma (SCC) tissues and oral cancer cell lines. We also investigated the prognostic significance of mGluR5 and its functional importance in the migration, invasion, and adhesion of oral cancer cells. We evaluated the expression of mGluR5 in samples from 131 oral SCC patients and in several oral cancer cell lines by immunohistochemistry and RT-PCR. We observed varying levels of mGluR5 in human oral SCC tissues and cancer cell lines. There was a significant association between strong mGluR5 immunoreactivity and overall survival $(\mathrm{P}=0.0109)$. The functional significance of the expression of mGluR5 in oral cancer cells was then investigated in HSC3 oral tongue cancer cells. An mGluR5 agonist, DHPG increased tumor cell migration, invasion, and adhesion in HSC3 cells $(\mathrm{P}<0.05)$. This was reversed by the mGluR5 antagonist MPEP. Our results strongly suggest that mGluR5 is a new prognostic marker and contributes to tumor cell migration and invasion in oral cancer.
\end{abstract}

\section{Introduction}

Squamous cell carcinoma (SCC) is the most common cancer of the head and neck and is the sixth most frequent cancer worldwide (1). Oral SCC, frequently observed at various

Correspondence to: Dr Sung-Weon Choi, Research Institute and Hospital, National Cancer Center, 809 Madu-1dong, Ilsandong-gu, Goyang-si, Gyeonggi-do 411-769, Korea

E-mail: choiomfs@ncc.re.kr

${ }^{*}$ Contributed equally

Key words: mGluR5, oral cancer, prognosis, migration, invasion, adhesion subsites in head and neck cancer, is characterized by a high degree of local invasion, cervical lymph node metastasis, and local recurrence after initial treatment, possibly due to microinvasion and/or micrometastasis (2). Clinical staging and cervical lymph node metastasis have been used as prognostic indicators in the management of oral cancer, but they have limited predictive value. Novel prognostic markers for assessing the biological aggressiveness of tumors are needed and should facilitate the individual tailoring of treatment.

There is increasing evidence that tumor growth, invasion, and metastasis are regulated by neurotransmitters that bind to serpine receptors, such as dopamine, somatostatin, substance $\mathrm{P}$, calcitonin gene-related peptide, neuropeptide $\mathrm{Y}$, and glutamate (3). Glutamate was originally identified as an excitatory neurotransmitter in the mammalian central nervous system, where it activates both ionotropic and metabotropic glutamate receptors. Ionotropic receptors include ligand-gated ion channels within the plasma membrane, whereas metabotropic glutamate receptors (mGluRs) are coupled to G-proteins and include eight subtypes (4). Abnormal glutamate signaling plays a critical role in the development and progression of diverse neurological disorders, such as Alzheimer's and Parkinson's diseases $(5,6)$.

Although glutamate and its receptors are predominantly found within the central nervous system, they also exist in nonneuronal cells outside the brain $(7,8)$. Glutamate signaling has been implicated in the growth and migration of various non-neuronal cancers (9-11). Rzeski and colleagues demonstrated that ionotropic glutamate receptor antagonists limit cell proliferation in various non-neuronal cancers, including colon, breast, lung, and thyroid (12). In addition, in two recent reports on melanoma tumorigenesis, Chen et al showed that the metabotropic glutamate receptor 1 (mGluR1) is ectopically expressed in a mouse model of TG3 melanoma $(13,14)$. Other studies have shown that mGluR1 and mGluR5 are up-regulated in metastatic melanoma and lung cancer, respectively (15). These reports imply that metabotropic glutamate receptors are important in tumor progression, but there is currently no direct evidence for a role of mGluR 1 and mGluR5 in oral cancer, even though glutamate receptors have been found in peripheral tissues and in different types of cancer. 
Although oral SCC has a different origin than melanoma or lung cancer, we extended these studies to oral cancer by examining the expression of mGluR1 and mGluR5 in oral cancer tissues and cell lines. Since we did not detect mGluR1 in oral cancer tissues and cell lines, we focused on the role of mGluR5 in oral cancer cell migration, invasion, and adhesion and the relationship between its expression and prognosis.

\section{Materials and methods}

Cell culture. Cal27 and KB human oral squamous cell carcinoma cell lines were obtained from American Type Cell Collection (Manassas, VA, USA). HSC-3, the human oral tongue squamous cell carcinoma cell line, was purchased from Japanese Cell Resource Bank. YD-17 and YD-10B oral squamous cell carcinoma cell lines were kindly donated by the Department of Oral Pathology, Dental College, Yonsei University (16). Cal27, KB and HSC-3 were cultured in Dulbecco's modified Eagle's medium (DMEM; Gibco, Brooklyn, MA) supplemented with $10 \%$ fetal bovine serum, $100 \mathrm{U} / \mathrm{ml}$ penicillin, and $100 \mu \mathrm{g} / \mathrm{ml}$ streptomycin. YD-17 and YD-10B were cultured in a 1:3 mixture of DMEM and F12. All cultures were maintained in a humidified atmosphere of $5 \%$ $\mathrm{CO}_{2}$ at $37^{\circ} \mathrm{C}$.

To evaluate the possible role of the mGluR5, we used mGluR5 agonist (DHPG, 3,5-dihydroxyphenylglycine) and antagonist (MPEP, 2-methyl-6-2-phenyl-1-ethynyl pyridine), which were purchased from Tocris (Bristol, UK).

Tumor specimens. Eight oral squamous cell carcinoma tissues were harvested at surgery and immediately snap frozen at $-80^{\circ} \mathrm{C}$ until RNA extraction. Institutional Review Board-approved, written informed consent was obtained from all the eight patients donating specimens for RNA extractions, through the Oral Cancer Clinic, National Cancer Center. In total, 131 oral squamous cell carcinoma tissue samples were obtained from patients who underwent primary surgery between 1996 and 2000 at the Department of Oral and Maxillofacial Surgery, College of Dentistry, Yonsei University. All specimens were fixed in formalin and paraffin-embedded. Carcinomas were morphologically classified according to WHO specifications. Staging was based on the TNM classification of the American Joint Committee of Cancer (AJCC) criteria of 1997. In all cases, final staging was adjusted on the basis of postoperative pathological reports. The clinical outcomes of the oral cancer patients were followed until death or August 31, 2005 and median follow-up time was 76 months (range 3-118 months).

Reverse transcriptase-polymerase chain reaction (RT-PCR). Total RNA was isolated from cells and tumor tissues with a RNeasy mini kit (Qiagen Sciences, MD, USA). RNA samples were stored at $-80^{\circ} \mathrm{C}$ until use. Reverse transcription was performed with $1 \mu 1$ total RNA using the SuperScript FirstStrand Synthesis System (Invitrogen). To determine mGluR1 mRNA expression, $2 \mu 1$ cDNA was amplified with 1.25 units of Takara EX Taq ${ }^{\mathrm{TM}}$ (Takara Bio Inc., Japan ) in a $25 \mu \mathrm{l}$ reaction containing $0.2 \mathrm{mmol} / \mathrm{l} \mathrm{dATP}, \mathrm{dCTP}, \mathrm{dGTP}$, and dTTP, and $2 \mathrm{mmol} / 1 \mathrm{MgCl}_{2}$. PCR was performed for 30 cycles ( $1 \mathrm{~min}$ at $95^{\circ} \mathrm{C}, 45 \mathrm{sec}$ annealing at $58^{\circ} \mathrm{C}, 2 \mathrm{~min}$ at $72^{\circ} \mathrm{C}$ ). The following primers were employed for amplification of mGluR1: amplimer $453 \mathrm{bp}$; forward, 5'-ACC CGG TCC TCC TGC CCA ACA-3', and reverse, 5'-CGT CCA TTC CGC TCT CCC CAT AA-3'. Electrophoresis was performed by loading $10 \mu \mathrm{l}$ of each sample on a $1.5 \%$ agarose gel, and proteins visualized by ethidium bromide staining using the Bio-imaging System (Ultra-Violet Products, UVP, Cambridge, UK).

Western blot analysis. Cells were washed twice with PBS, and lysed in RIPA buffer (150 mM NaCl, $50 \mathrm{mM}$ Tris-HCl, $\mathrm{pH} 7.4$, $2.5 \%$ deoxycholic acid, 10\% NP-40, 10 mM EDTA) for the detection of mGluR5 protein. Proteins were separated by SDS polyacrylamide gel electrophoresis $(7.5 \%)$, and transferred to nitrocellulose membrane (BioRad, Italy) for $1 \mathrm{~h}$. Filters were blocked overnight in Tween-20 Tris-buffered saline (TTBS; $100 \mathrm{mM}$ Tris- $\mathrm{HCl}, 0.9 \% \mathrm{NaCl}, 1 \%$ Tween-20, $\mathrm{pH} 7.4$ ) containing $4 \%$ non-fat dry milk. Blots were incubated for $2 \mathrm{~h}$ at room temperature with primary antibody against mGluR5 (1:1000, Upstate Biotechnology, Lake Placid, NY, USA), washed 3 times with TTBS buffer, and incubated for $1 \mathrm{~h}$ with peroxidase-coupled anti-rabbit secondary antibody (Upstate Biotechnology). Immunoreactive bands were visualized by enhanced chemiluminescence (ECL) according to the specifications of the manufacturer (Amersham Biosciences, Piscataway, NJ).

Immunohistochemistry. Sections $(4 \mu \mathrm{m})$ were deparaffinized, rehydrated in graded alcohol, and processed using the avidin-biotin immunoperoxidase method. Briefly, antigen was retrieved by exposure in a microwave oven for $15 \mathrm{~min}$ in $10 \mathrm{mM}$ citrate buffer, $\mathrm{pH}$ 6.0. Endogenous peroxidase activity was blocked with a $3 \% \mathrm{H}_{2} \mathrm{O}_{2}$-methanol solution, and slides incubated in $10 \%$ normal goat serum for $30 \mathrm{~min}$ to prevent non-specific staining. Sections were incubated with a primary polyclonal antibody against mGluR5 (1:100 dilution, Upstate Biotechnology) for $1 \mathrm{~h}$ at room temperature, followed by treatment with biotinylated secondary antibodies and avidinbiotin peroxidase complexes for $30 \mathrm{~min}$. Diaminobenzidine was used as the chromogen and Mayer's hematoxylin as counterstain. As a negative control, non-immune serum was substituted for the primary antibody. Human brain cortex was employed as a positive control. The specificity of mGluR5 antibodies has been reported (17). Both membranous and/or cytoplasmic expression of mGluR5 were regarded as positive. Immunostaining was evaluated by two pathologists. Based on the percentage of immunostained cancer cells and staining intensity, the following grades were issued: 0 (negative), no or weak staining in $<10 \%$ of tumor cells: $1+$ (weakly positive), weak to moderate staining in $>10 \%$ of tumor cells: $2+$ (strongly positive), strong staining in $>10 \%$ of tumor cells.

Flow cytometry. HSC3 cells was adjusted to a concentration of $2 \times 10^{7}$ cells $/ \mathrm{ml}$ in FACS buffer (PBS containing $0.5 \%$ BSA and $0.05 \%$ sodium azide). The cells were incubated for $1 \mathrm{~h}$ at room temperature with primary anti-mGluR5 polyclonal antibody (Upstate Biotechnology) and washed with PBS and followed by incubation with secondary Alexa ${ }^{\mathrm{TM}} 488$ conjugated goat anti-rabbit antibody (Molecular Probes, Eugene, OR, USA) for $1 \mathrm{~h}$ at room temperature. Negative 


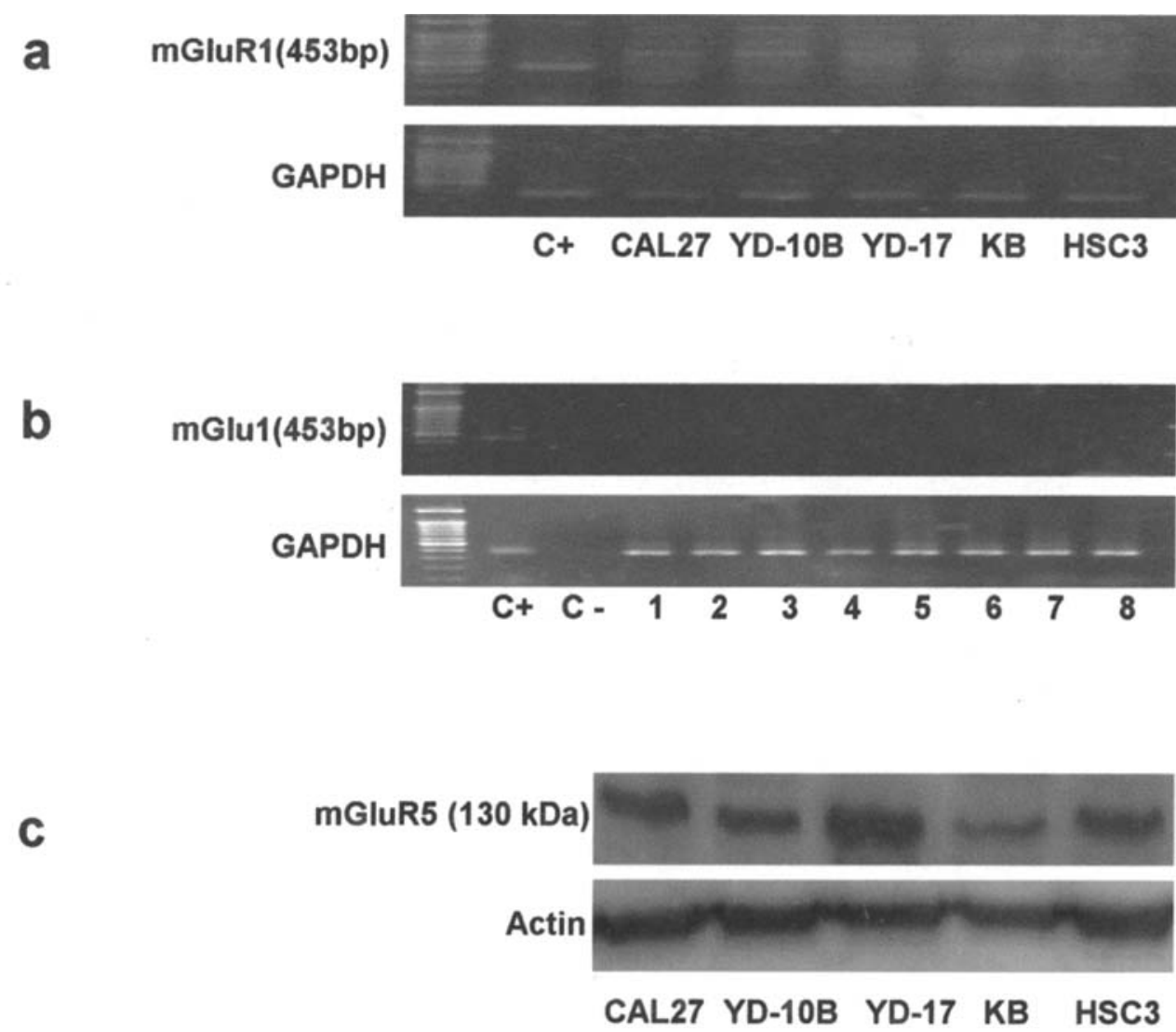

Figure 1. Expression of mGluR1 and mGluR5 in oral cancer cell lines and tissues. Transcripts for mGluR1 were not detected in oral cancer cells (a) and oral cancer tissues (b) by RT-PCR. C+, human cerebral cortex (positive control); C-, diethyl pyrocarbonate-treated water $\mathrm{H}_{2} \mathrm{O}$ (negative control); lanes $1-8$, tumor tissue samples from eight patients. (c) Expression of mGluR5 protein in the cell lines was confirmed by Western blot analysis.

controls consisted of cells in the absence of primary antibody. Fluorescence was detected by flow cytometry on a FACSCalibur (Becton Dickinson, Heidelberg, Germany) and analysed using Cell Quest software.

Immunofluorescence staining of mGluR5. Cells were plated on glass cover slips for $24 \mathrm{~h}$. After washing with cold PBS, samples were fixed with $3.8 \%$ paraformaldehyde, permeabilized with cold $0.2 \%$ Triton $\mathrm{X}-100$ for $10 \mathrm{~min}$ at room temperature, and washed in PBS. Cells were incubated for $1 \mathrm{~h}$ at room temperature with primary anti-mGluR5 polyclonal antibody (Upstate Biotechnology), and washed twice with PBS, followed by incubation with secondary Alexa 488-labeled goat anti-rabbit IgG antibody (Molecular Probes) for $1 \mathrm{~h}$ at room temperature. Confocal microscopy was performed using LSM 50 (Zeiss, Oberkochen, Germany).

Migration assay. Migration of HSC3 cells were assayed using $6.5 \mathrm{~mm}$ Transwell chambers with $8 \mu \mathrm{m}$ pore filters (Transwell, 24-well cell culture, Coster, Cambridge, MA). Cells (1x106) were resuspended in DMEM containing serum-free 0.1\% BSA, and added to the upper compartment of each Transwell. Next, $10,50,100 \mu \mathrm{M}$ DHPG with or without MPEP was added to the lower compartment of each Transwell, while $0.5 \mathrm{ml} 0.1 \%$ BSA-containing media were added to the lower chamber. After $17 \mathrm{~h}$ of incubation at $37^{\circ} \mathrm{C}$, cells on the upper surface of the filter were removed with a cotton swab, and filters were fixed and stained with Diff-Quick reagent (Dade Behring, Dugen,
Switzerland). The number of migrating cells in 10 fields per filter was counted microscopically at x100 magnification.

Invasion assay. Invasion of cancer cells was assayed using a Biocat Matrigel invasion chamber (Becton Dickinson, Bedford, MA), which consists of an $8 \mu \mathrm{m}$ pore size polyethylene terephthalate (PET) membrane that has been overlaid with Matrigel (basement membrane metrix). HSC-3 cells $\left(1 \times 10^{6}\right)$ were resuspended in DMEM containing serum-free $0.1 \%$ BSA, and added to the upper compartment of each Transwell. Next, $10,50,100 \mu \mathrm{M}$ DHPG with or without MPEP was added to the lower compartment of each Transwell, while $0.5 \mathrm{ml} 0.1 \%$ BSA-containing media were added to the lower chamber. After $17 \mathrm{~h}$ of incubation at $37^{\circ} \mathrm{C}$, cells on the upper surface of the filter were removed with a cotton swab, and filters were fixed and stained with Diff-Quick reagent (Dade Behring). The number of migrating cells in 10 fields per filter was counted microscopically at x100 magnification.

Adhesion assay. The adhesion of oral cancer cells to the elements of extracellular matrix (ECM) was evaluated. Oral cancer cells were grown to subconfluent state and then harvested by $0.25 \%$ trypsin/EDTA (Invitrogen Corp., Carlsbad, CA). Cells were preincubated with DHPG or with DHPG plus MPEP for $3 \mathrm{~h}$. Preincubated cells were plated onto a 96-well microplate which was precoated with various ECM elements, that is, $0.01 \mathrm{mg} / \mathrm{ml}$ fibronectin, collagen IV (BectonDickinson Japan, Todyo, Japan). Then the cells were incubated 
for $2 \mathrm{~h}$ at $37^{\circ} \mathrm{C}$ in $5 \% \mathrm{CO}_{2} / 95 \%$ air to allow cell attachment. Cells were washed gently with PBS 3 times to remove detached cells. The number of adherent cells was measured by MTT assay. Experiments were repeated 3 times in triplicate wells.

Statistical analysis. The association between immunohistochemical staining grade and clinicopathological factors was assessed with the $\chi^{2}$ and ANOVA tests. To establish the overall survival rate related to mGluR5 expression, the Kaplan-Meier method was employed for survival analysis. Differences in survival rate were evaluated using the log-rank test. Multivariate analysis was performed using the Cox proportional hazards regression model. Differences in cell migration, invasion and adhesion were assessed with the unpaired Student's t-test. $\mathrm{P}<0.05$ was considered significant in all statistical analyses.

\section{Results and Discussion}

To examine the role of mGluR 1 and mGluR5 in oral cancer, we first examined their expression in oral cancer cells and SCC tissues by RT-PCR. We were not able to detect mGluR1 transcripts in oral cancer cells (Fig. 1a and b). Further examination of five human oral cancer cell lines by Western blotting showed that they express various amounts of mGluR5 protein (Fig. 1c).

Immunohistochemical staining of oral SCC tissues showed no or very weak expression of mGluR5 in the basal layer of normal oral squamous cell epithelium (Fig. 2a). In oral cancer tissues, mGluR5 immunoreactivity was localized specifically in carcinoma cells (Fig. 2c-e). Moreover, the dysplastic mucosa adjacent to the main cancer lesion displayed weak staining of membranes that was confined to dysplastic cells (Fig. 2b). The staining for mGluR5 was mostly concentrated in the cell membrane, but cytoplasmic staining was observed in some specimens. Of the 131 cases of oral cancer examined, $37(28 \%)$ displayed negative mGluR5 expression, 52 (40\%) were weakly positive $(1+)$, and $42(32 \%)$ exhibited strongly positive expression (2+) of mGluR5.

Chen et al reported that, in melanoma, ectopically expressed mGluR1 participates in tumorigenesis and that mGluR5 is not oncogenic $(13,14)$. Herein we found that only mGluR5 is expressed in oral cancer cells and tumors. This suggests that different mGluRs participate in the progression of different types of cancer. Microarray analysis has demonstrated that mGluR5 is overexpressed in lung adenocarcinoma (15). The current study is the first to examine the expression of mGluR5 in human cancer tissues.

Interestingly, we found a correlation between strong positive expression of mGluR5 and $\mathrm{T}$ stage T3/T4 $(\mathrm{P}<0.0001)$ and AJCC stage III/IV $(\mathrm{P}<0.0001)$. In contrast, mGluR5 expression was not significantly associated with smoking, sex, age, tumor differentiation, or lymph node metastasis (Table I). A significant association between mGluR5 expression and advanced AJCC stages (III and IV) suggests that mGluR5 is involved in progression of the primary tumor, consistent with recent reports that glutamate and its receptors are involved in tumor growth in vitro (10). Univariate analysis revealed that increased expression of mGluR5 correlated significantly
Table I. Correlation between mGluR5 expression and clinicopathological factors.

\begin{tabular}{|c|c|c|c|c|}
\hline & \multicolumn{3}{|c|}{ mGluR5 } & \multirow[b]{2}{*}{$\mathrm{P}$} \\
\hline & Negative & $1+$ & $2+$ & \\
\hline \multicolumn{5}{|l|}{ Age (years) } \\
\hline$<60$ & 21 & 25 & 19 & $\mathrm{P}=0.315$ \\
\hline$\geq 60$ & 16 & 27 & 23 & \\
\hline \multicolumn{5}{|l|}{ Sex } \\
\hline Male & 25 & 41 & 33 & $\mathrm{P}=0.270$ \\
\hline Female & 12 & 11 & 9 & \\
\hline \multicolumn{5}{|c|}{ Tumor differentiation } \\
\hline Well & 24 & 28 & 26 & $\mathrm{P}=0.697$ \\
\hline Moderate/poorly & 13 & 24 & 16 & \\
\hline \multicolumn{5}{|l|}{ Tumor size } \\
\hline $\mathrm{T} 1 / \mathrm{T} 2$ & 26 & 35 & 12 & $\mathrm{P}<0.0001$ \\
\hline $\mathrm{T} 3 / \mathrm{T} 4$ & 11 & 17 & 30 & \\
\hline \multicolumn{5}{|c|}{ Lymph node metastasis } \\
\hline Absent & 28 & 27 & 24 & $\mathrm{P}=0.108$ \\
\hline Present & 9 & 25 & 18 & \\
\hline \multicolumn{5}{|l|}{ Stage } \\
\hline $\mathrm{I} / \mathrm{II}$ & 22 & 21 & 6 & $\mathrm{P}<0.0001$ \\
\hline III/IV & 15 & 31 & 36 & \\
\hline
\end{tabular}

(log-rank, $\mathrm{P}=0.0109$ ) with a decreased 5-year survival rate compared with cases showing negative expression of mGluR5 (Fig. 3). In addition, the multivariate Cox proportional hazards model showed that there was a significant association between poor survival and lymph node metastasis $(\mathrm{P}=0.016)$ and mGluR5 expression ( $\mathrm{P}=0.026$ and 0.038 for $1+$ and $2+$ levels of mGluR5 vs. mGluR5-negative samples) but that there was not a significant association between poor survival and age, sex, primary site, or T stage (Table II). Close followup studies and aggressive treatment may be necessary in patients expressing high levels of mGluR5, but the mechanism underlying the poor prognosis in these patients remains to be determined.

We also performed a variety of functional studies to determine the phenotype of mGluR5-expressing oral cancer cells. We examined the effects of an agonist, DHPG and an antagonist, MPEP, of mGluR5 on the migration, invasion, and adhesion of HSC3 oral tongue cancer cells. Treatment of the cells for $24 \mathrm{~h}$ with 10,50 , or $100 \mu \mathrm{M}$ DHPG agonist did not affect their proliferation, and a 24-h treatment with $100 \mu \mathrm{M}$ DHPG had no effect on their viability or cell proliferation (data not shown). As shown in Fig. 4b and c, DHPG dosedependently enhanced the migration and invasiveness of the HSC 3 cells $(\mathrm{P}<0.05)$. This was inhibited by MPEP $(\mathrm{P}<0.05)$. In addition, DHPG dose-dependently stimulated the adhesion of the cells to collagen type IV and fibronectin (Fig. $4 \mathrm{~d}$ and e). Cancer cells invade tissues by first migrating from their primary sites. Thus, the enhancement of cell migration, 
a

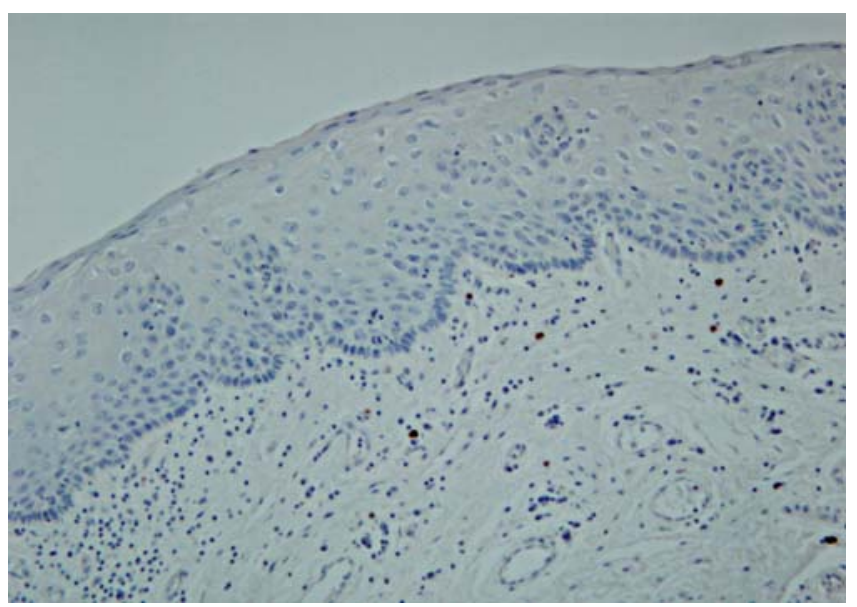

b

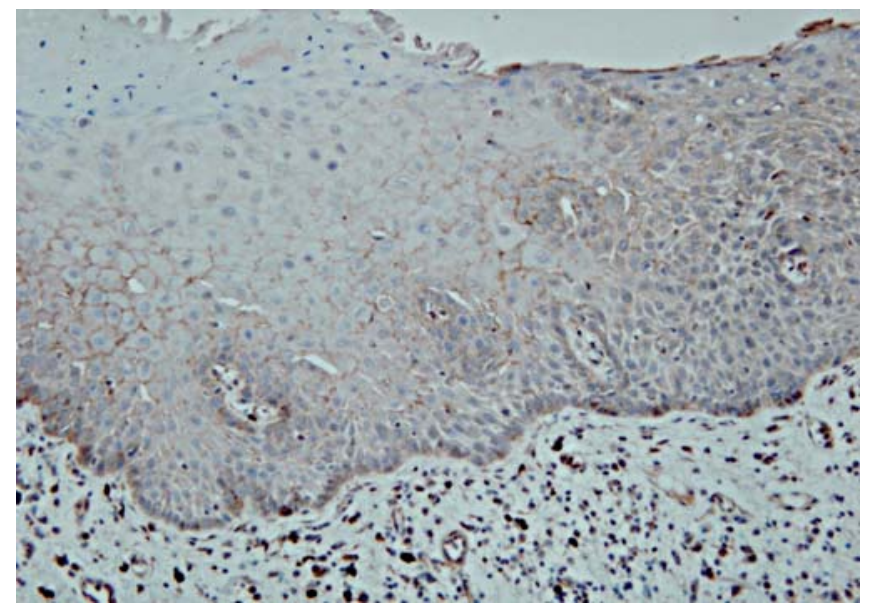

c

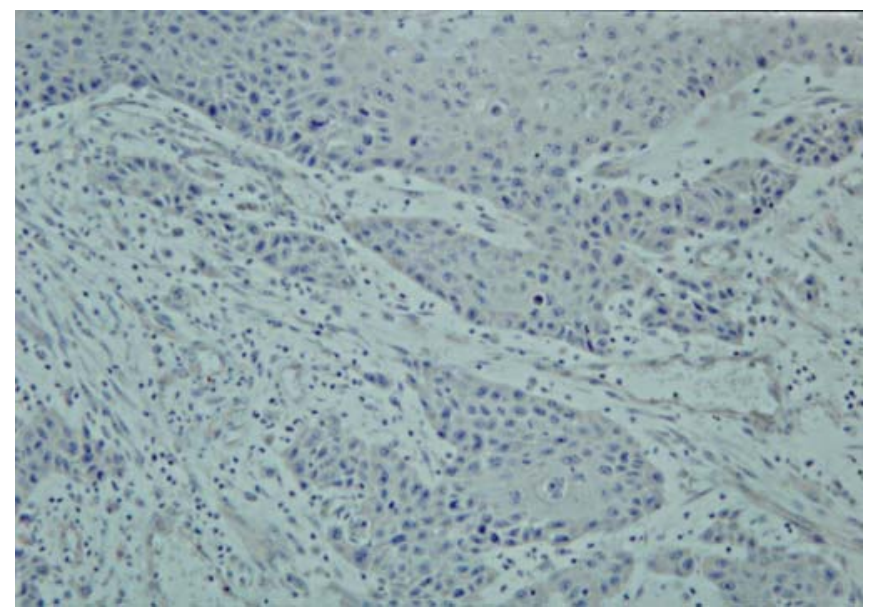

d

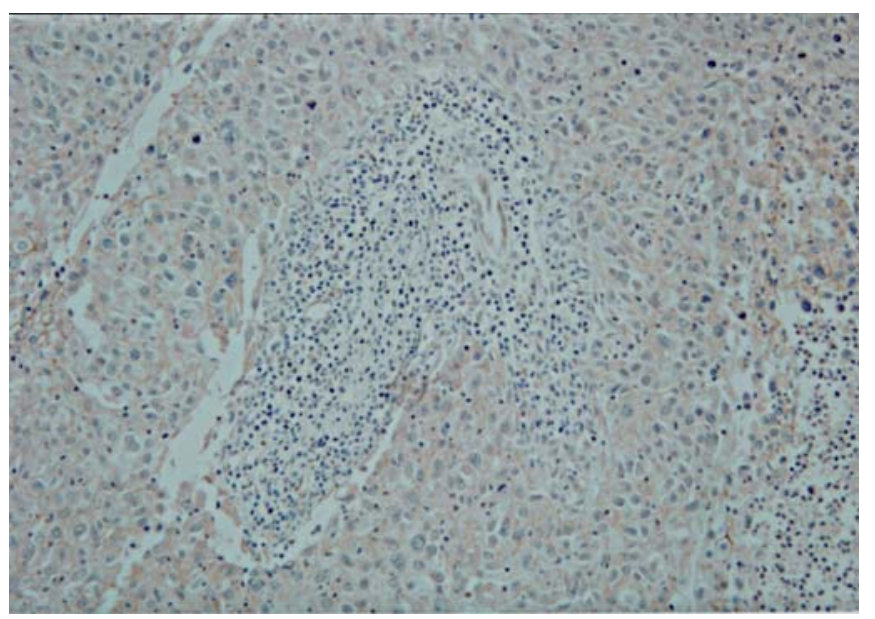

e

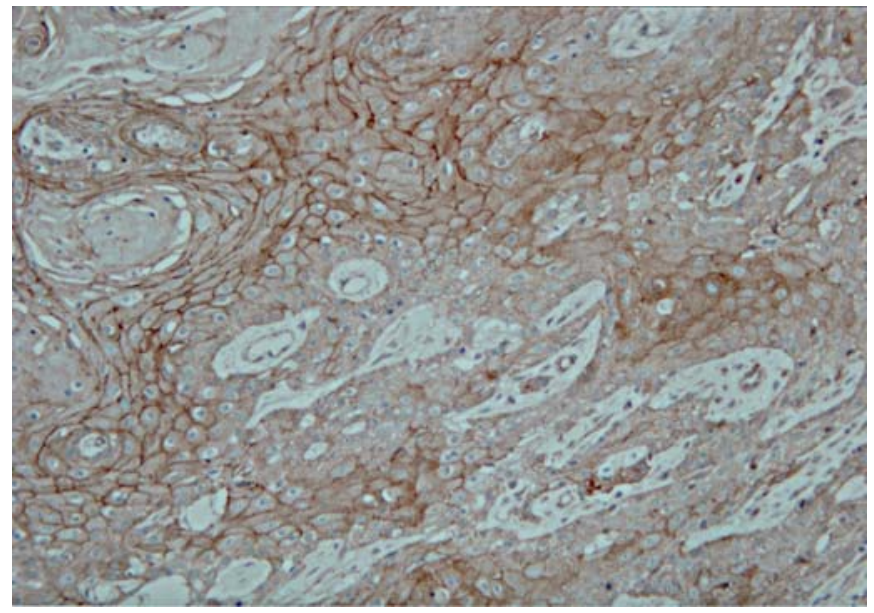

f

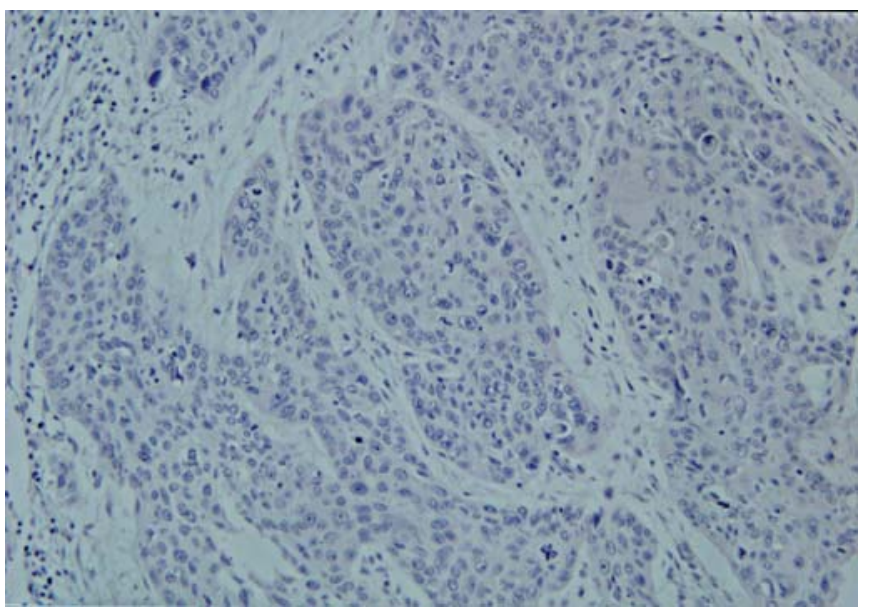

Figure 2. Immunohistochemical analysis of mGluR5 expression in human oral SCC tissues. (a) Normal oral epithelium showing very weak staining in the basal layer and discrete staining of melanocytes. (b) A dysplastic lesion adjacent to the cancer lesion. (c) Oral SCC displaying negative mGluR5 expression. (d) Oral SCC with weakly positive expression (1+). (e) Oral SCC showing strongly positive expression (2+) localized predominantly in the cell membrane, although cytoplasmic staining is observed in some cases. (f) Negative control. Original magnification, x200.

invasion, and adhesion of oral cancer cells with DHPG supports the idea that mGluR5 signaling is important in the invasion and metastasis of oral cancer.
The mGluRs are members of the large family of seventransmembrane domain $\mathrm{G}$ protein-coupled receptors, which can be divided into three subtypes according to their sequences and 


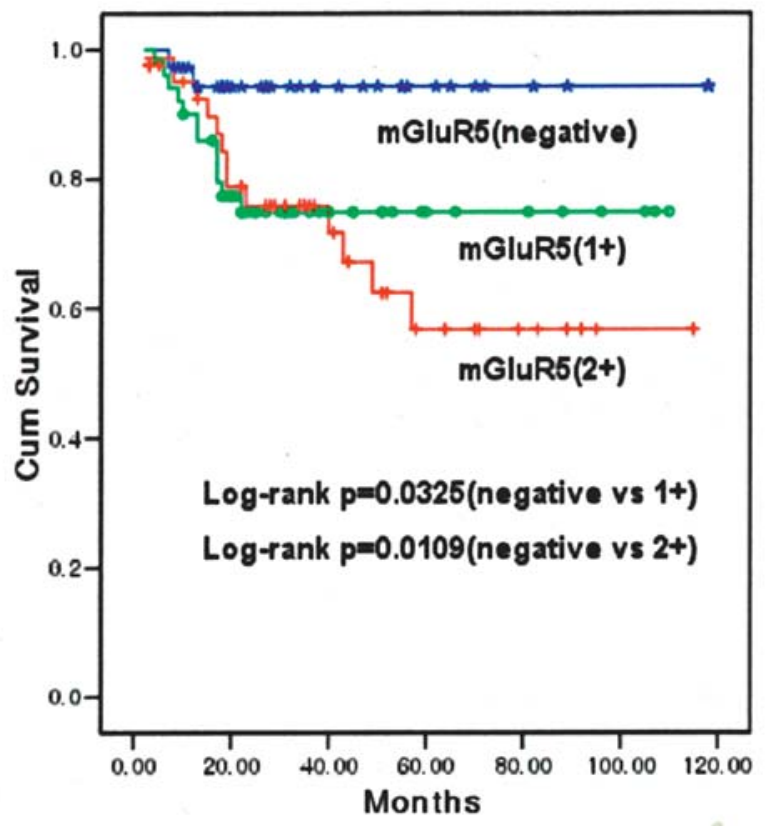

Figure 3. Kaplan-Meier survival curve of oral SCC patients in relation to mGluR5 immunoreactivity. Patients with oral SCC tissues strongly positive for mGluR5 expression have a decreased survival rate compared to those with tissues showing negative expression of mGluR5 $(\mathrm{P}=0.0109)$.

intracellular effector systems (18). Both mGluR1 and mGluR5 are members of Group I mGluRs, proteins that are coupled to multiple intracellular signaling pathways, including phospholipase $\mathrm{C}$, which stimulates the production of inositol 1,4,5-triphosphate and diacylglycerol, leading to the activation of protein kinase $\mathrm{C}(13)$. These downstream signaling pathways may contribute to the migration and invasive phenotype of mGluR5-expressing cells in oral cancer. Although there is limited evidence that mGluR5 participates in tumor progression, various G-protein coupled receptors are known to be ectopically expressed, overexpressed, or mutated in some tumors (19). These studies and our current results indicate that mGluR5 may be a novel therapeutic target in various cancers.

In conclusion, we found that mGluR5 is not only frequently overexpressed in oral SCC but also may be involved in tumor progression and that its expression may be linked to prognosis. Thus, mGluR5 may be a new prognostic marker and may play a role in the invasiveness of oral SCC.

a

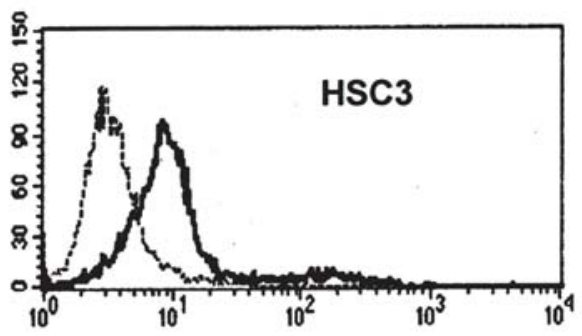

b

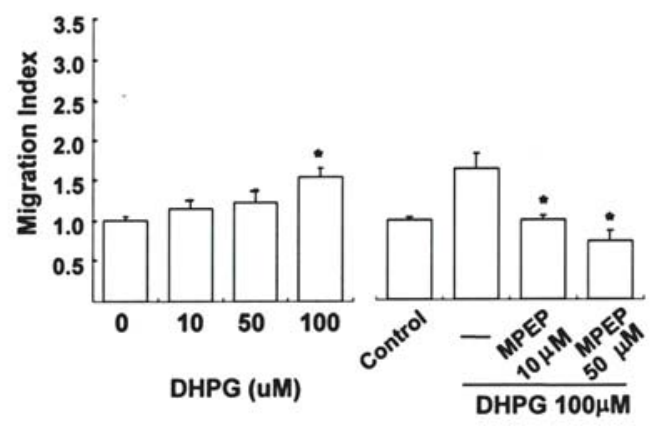

d

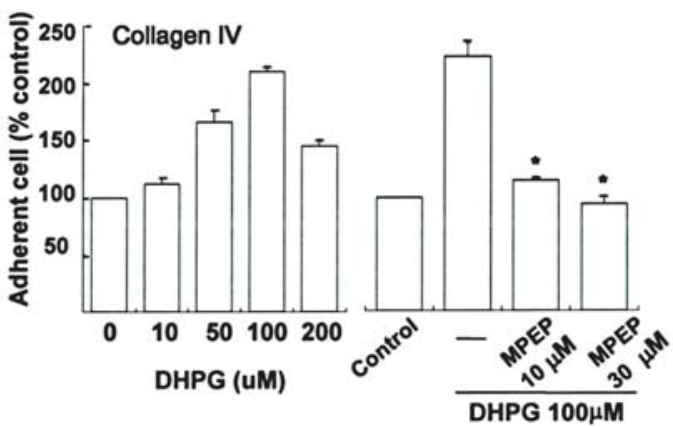

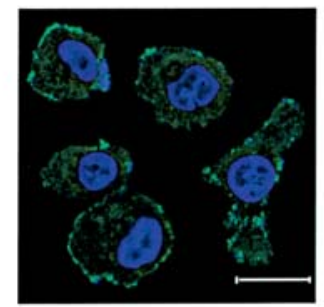

C

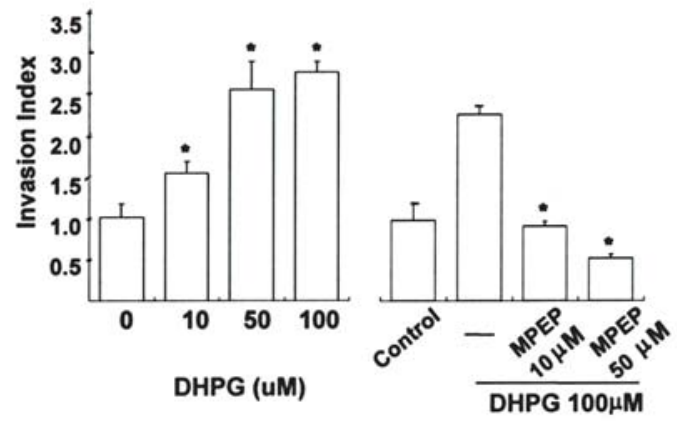

e

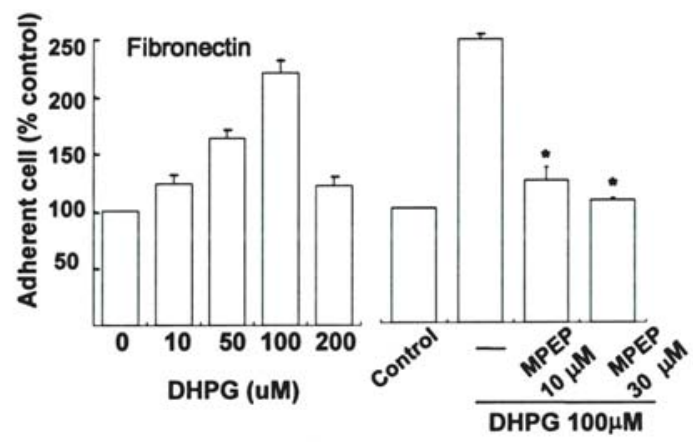

Figure 4. Effect of an mGluR5 agonist, DHPG, and antagonist, MPEP, on the migration, invasion, and adhesion of HSC3 oral tongue cancer cells. (a) Expression of mGluR5 in HSC3 cells as assessed by flow cytometry and confocal microscopy. Bar, $10 \mu \mathrm{m}$. (b) Migration of HSC3 cells. DHPG stimulated cell migration. This effect of DHPG was inhibited by MPEP. (c) DHPG enhanced the invasiveness of HSC3 cells, and this effect of DHPG was suppressed by MPEP. (d and e) Adhesion of cells. DHPG enhanced the number of cells adhering to collagen IV (d) and fibronectin (e), and these effects of DHPG were inhibited by MPEP. In all panels, results represent means \pm standard deviation from three independent experiments. ${ }^{*} \mathrm{P}<0.05$ vs. control or $100 \mu \mathrm{M}$ DHPG. 
Table II. Cox proportional hazards model for overall survival.

\begin{tabular}{|c|c|c|c|c|}
\hline \multirow[b]{2}{*}{ Parameters } & \multicolumn{4}{|c|}{ Multivariate anaysis } \\
\hline & Case No. & $\begin{array}{c}\text { Univariate } \\
\text { analysis }(\mathrm{P})\end{array}$ & $\begin{array}{l}\text { Hazard ratio } \\
(95 \% \mathrm{Cl})\end{array}$ & $\mathrm{P}$ \\
\hline mGluR5 & & 0.0389 & & \\
\hline Negative & 37 & & & \\
\hline $1+$ & 52 & & $5.225(1.096-24.912)$ & 0.038 \\
\hline $2+$ & 42 & & $6.096(1.236-30.061)$ & 0.026 \\
\hline Age (years) & & 0.7172 & $1.499(0.676-3.321)$ & 0.319 \\
\hline$<60$ & 66 & & & \\
\hline$\geq 60$ & 65 & & & \\
\hline Sex & & 0.8797 & $2.077(0.780-5.532)$ & 0.144 \\
\hline Male & 99 & & & \\
\hline Female & 32 & & & \\
\hline Tumor size & & 0.0452 & $2.490(0.977-6.346)$ & 0.056 \\
\hline $\mathrm{T} 1 / \mathrm{T} 2$ & 73 & & & \\
\hline $\mathrm{T} 3 / \mathrm{T} 4$ & 58 & & & \\
\hline Tumor differentiation & & 0.5800 & & \\
\hline Well & 78 & & & \\
\hline Moderate/poorly & 53 & & & \\
\hline Lymph node metastasis & & 0.0178 & $2.949(1.224-7.108)$ & 0.016 \\
\hline Absent & 79 & & & \\
\hline Present & 52 & & & \\
\hline
\end{tabular}

CI, confidence interval.

\section{Acknowledgements}

This work was supported by a grant (0410460) from the National Cancer Center.

\section{References}

1. Johnson NW: Oral cancer: a worldwide problem. FDI World 6: 19-21, 1997.

2. Almofti A, Uchida D, Milabegum N, Tomizuka Y, IGA Hiroki, Yoshida $\mathrm{H}$ and Sato M: The clinicopathological significance of the expression of CXCR4 protein in oral squamous cell carincoma. Int J Oncol 25: 65-71, 2004.

3. Entschlade F, Lang K, Drell TL, Joseph J and Zaenker KS: Neurotransmitters are regulators for the migration of tumor cells and leukocytes. Cancer Immunol Immunother 51: 467-482, 2002.

4. Nakanishi N, Shneider NA and Axel R: A family of glutamate receptor genes: evidence for the formation of heteromultimeric receptors with distinct channel properties. Neuron 5: 569-581, 1990.

5. Lee JM, Zipfel GJ and Choi DW: The changing landscape of ischaemic brain injury mechanisms. Nature 399: A7-A14, 1999.

6. Kumoro $\mathrm{H}$ and Rakic P: Modulation of neuronal migration by NMDA receptors. Science 260: 95-97, 1990.

7. Skerry TM and Genever PG: Glutamate signaling in non-neuronal tissues. Trend Pharmacol Sci 22: 174-181, 2001.

8. Hinoi E, Takarada T, Ueshima T, Tsuchihashi Y and Yoneda Y: Glutamate signaling in peripheral tissues. Eur J Biochem 271: $1-13,2004$.

9. Cavalheiro EA and Olney JW: Glutamate antagonists: deadly liaisons with cancer. Proc Natl Acad Sci USA 98: 5947-5948, 2001.
10. Ishiuchi S, Tsuzuki K, Yoshida Y, Yamada N, Hagimura N, Okado H, Miwa A, Kurihara H, Nakazato Y, Tamura M, Sasaki T and Ozawa S: Blockage of $\mathrm{Ca}^{2+}$-permeable AMPA receptor suppress migration and induces apoptosis in human glioblastoma cells. Nat Med 8: 971-978, 2002.

11. Sontheimer H: Malignant gliomas: perverting glutamate and ion homeostasis for selective advantage. Trends Neurosci 26: 543-549, 2003.

12. Rzeski W, Turski L and Ikonomidou C: Glutamate antagonist limit tumor growth. Proc Natl Acad Sci USA 98: 6372-6377, 2001.

13. Pollock PM, Cohen-Solal K, Sood R, Namkoong J, Martino JJ, Koganti A, Zhu H, Robbins C, Makalowska I, Shin SS, Martin Y and Roberts KG: Melanoma mouse model implicates metabotropic glutamate signaling in melanocytic neoplasia. Nat Genet 34: 108-112, 2003.

14. Marin YE, Namkoong J, Shin SS, Raines J, Degenhardt K, White $\mathrm{E}$ and Chen S: Grm5 expression is not required for the oncogenic role of Grm1 in melanocytes. Neuropharmacology 49: 70-79, 2005.

15. Li S, Huang S and Peng SB: Overexpression of G protein-coupled receptors in cancer cells: involvement in tumor progression. Int J Oncol 27: 1329-1339, 2005.

16. Lee EJ, Kim J, Lee SA, Kim EJ, Chun YC, Ryu MH and Yook JI: Characterization of newly established oral cancer cell lines derived from six squamous cell carcinoma and two mucoepidermoid carcinoma cells. Exp Molecular Med 37: 379-390, 2005.

17. Gereau RW and Heinemann SF: Role of protein kinase C phosphorylation in rapid desensitization of metabotropic glutamate receptor 5. Neuron 20: 143-151, 1998.

18. Schoepp DD, Jane DE and Monn JA: Pharmacological agents acting at subtypes of metabotropic glutamate receptors. Neuropharmacology 38: 1431-1476, 1999.

19. Marinissen MJ and Gutkind JS: G-protein coupled receptor and signaling networks: emerging paradigms. Trends Pharmacol Sci 22: 368-376, 2001. 